\title{
Recombinant Irisin Prevents the Reduction of Osteoblast Differentiation Induced by Stimulated Microgravity through Increasing $\beta$-Catenin Expression
}

\author{
Zhihao Chen $1,2,3,4,+$, Yan Zhang ${ }^{1,2,3,4,+}$, Fan Zhao ${ }^{1,2,3,4}$, Chong Yin 1,2,3,4 , Chaofei Yang 1,2,3,4, \\ Xue Wang 1,2,3,4 Zixiang Wu 1,2,3,4, Shujing Liang 1,2,3,4, Dijie Li 1,2,3,4 ${ }^{\mathbb{D}}$, Xiao Lin 1,2,3,4,

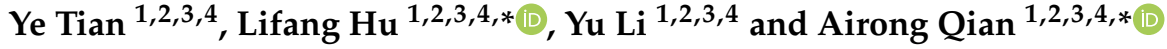 \\ 1 Lab for Bone Metabolism, Key Lab for Space Biosciences and Biotechnology, School of Life Sciences, \\ Northwestern Polytechnical University, Xi'an 710072, China; chzhh@mail.nwpu.edu.cn (Z.C.); \\ zhangyan0911@mail.nwpu.edu.cn (Y.Z.); sofan@mail.nwpu.edu.cn (F.Z.); \\ yinchong42@mail.nwpu.edu.cn (C.Y.); yangchaofei@mail.nwpu.edu.cn (C.Y.); \\ wangxue1005@mail.nwpu.edu.cn (X.W.); wuzx@mail.nwpu.edu.cn (Z.W.); liangsj@mail.nwpu.edu.cn (S.L.); \\ lidijie@mail.nwpu.edu.cn (D.L.); linxiao@nwpu.edu.cn (X.L.); tianye@nwpu.edu.cn (Y.T.); \\ liyu@nwpu.edu.cn (Y.L.) \\ 2 Xi'an Key Laboratory of Special Medicine and Health Engineering, School of Life Sciences, Northwestern \\ Polytechnical University, Xi'an 710072, China \\ 3 Research Center for Special Medicine and Health Systems Engineering, School of Life Sciences, \\ Northwestern Polytechnical University, Xi'an 710072, China \\ 4 NPU-UAB Joint Laboratory for Bone Metabolism, School of Life Sciences, Northwestern Polytechnical \\ University, Xi' an 710072, China \\ * Correspondence: hulifang@nwpu.edu.cn (L.H.); qianair@nwpu.edu.cn (A.Q.); Tel.: +86-029-8849-1840 (A.Q.) \\ + These authors contributed equally to this work.
}

Received: 26 January 2020; Accepted: 12 February 2020; Published: 13 February 2020

\begin{abstract}
Background: Irisin, a novel exercise-induced myokine, was shown to mediate beneficial effects of exercise in osteoporosis. Microgravity is a major threat to bone homeostasis of astronauts during long-term spaceflight, which results in decreased bone formation. Methods: The hind-limb unloading mice model and a random position machine are respectively used to simulate microgravity in vivo and in vitro. Results: We demonstrate that not only are bone formation and osteoblast differentiation decreased, but the expression of fibronectin type III domain-containing 5 (Fdnc5; irisin precursor) is also downregulated under simulated microgravity. Moreover, a lower dose of recombinant irisin (r-irisin) $(1 \mathrm{nM})$ promotes osteogenic marker gene (alkaline phosphatase (Alp), collagen type 1 alpha-1(Coll $\alpha 1)$ ) expressions, ALP activity, and calcium deposition in primary osteoblasts, with no significant effect on osteoblast proliferation. Furthermore, r-irisin could recover the decrease in osteoblast differentiation induced by simulated microgravity. We also find that r-irisin increases $\beta$-catenin expression and partly neutralizes the decrease in $\beta$-catenin expression induced by simulated microgravity. In addition, $\beta$-catenin overexpression could also in part attenuate osteoblast differentiation reduction induced by simulated microgravity. Conclusions: The present study is the first to show that r-irisin positively regulates osteoblast differentiation under simulated microgravity through increasing $\beta$-catenin expression, which may reveal a novel mechanism, and it provides a prevention strategy for bone loss and muscle atrophy induced by microgravity.
\end{abstract}

Keywords: irisin; simulated microgravity; osteoblast differentiation; $\beta$-catenin; bone loss 


\section{Introduction}

Disuse osteoporosis is a worldwide clinically relevant problem for those with a lack of mechanical load (e.g., bedridden, microgravity, aging) [1-4]. It is well known that microgravity results in decreased bone mineral density (BMD) and leads to bone loss during long-term spaceflight [5]. Bone, as a specifically gravity sensory organ, is mainly composed of osteocytes and osteoblasts that respond to and adapt to changes in gravity [6,7]. Many studies demonstrated that simulated microgravity leads to decreased osteoblast differentiation or bone formation [8-10], while the cellular and molecular mechanisms are not yet completely understood.

According to reports, there are many osteoporosis risk factors such as cytokines (e.g., interleukin) [11,12], hormones (e.g., parathyroid hormone) [13], and signaling pathways molecules (e.g., wingless-type MMTV integration site family (Wnt), bone morphogenetic protein(BMP)) [14,15], regulating bone metabolism under microgravity environment. Skeletal muscles and bone, as neighboring tissues, are the two largest tissues in the musculoskeletal system [12]. Muscle atrophy preceding bone loss is also induced by microgravity [16]. Especially for long-duration spaceflight astronauts, recovery from muscle atrophy is faster than that from bone loss [17]. There is increasing evidence that muscle-derived humoral factors, i.e., myokines (a kind of cytokine released from muscle), serve as important regulators of bone metabolism [12,18], such as interleukin-6 (IL-6), osteoglycin, and irisin [19].

Irisin is a novel hormone-like molecule released from skeletal muscle after physical exercise. It is cleaved from the extracellular domain of the transmembrane receptor fibronectin type III domain-containing 5 (FNDC5) and secreted from skeletal muscle into the bloodstream [20]. A positive correlation between irisin level and BMD was reported in the serum of young women [21] and plasma of Chinese elderly men [22]. Recent studies indicated that irisin displays anabolic actions on the skeleton through the stimulation of osteoblast differentiation and bone formation [23-27]. Significantly, Colaianni et al. found that recombinant irisin (r-irisin) could effectively prevent bone loss induced by hind-limb unloading in vivo. The BMD of both the cortical and the trabecular bone volume fraction (BV/TV) are also prevented by r-irisin injection [26]. In addition, FNDC5 messenger RNA (mRNA) level was decreased in the soleus muscle of hind-limb unloading mice. Furthermore, regression analysis suggested that the FNDC5 level of the soleus muscle was positively related to tibia trabecular BMD [28]. Therefore, the mechanism of irisin in osteoblast differentiation and bone formation under microgravity warrants an investigation.

Previous studies showed that $\mathrm{Wnt} / \beta$-catenin signaling is a key signaling pathway in osteoblast differentiation and bone formation [29-33]. In osteoblasts, mechanical stimulation causes a rapid, transient accumulation of active $\beta$-catenin in the cytoplasm and its translocation into the nucleus [34,35], and $\beta$-catenin is also sensitive to simulated microgravity $[14,36]$. It was reported that irisin influences adipogenesis through regulating the $\mathrm{Wnt} / \beta$-catenin signaling pathway [37], and it increases $\beta$-catenin expression during osteogenic differentiation [27]. These findings bring up an intriguing possibility that irisin may be involved in the process of osteoblast differentiation through altering $\beta$-catenin under simulated microgravity condition.

In this study, the hind-limb unloading mice model and a random position machine (RPM) were used to simulate microgravity in vivo and in vitro, respectively. Here, we firstly identified that Fdnc5 (irisin precursor) expression was decreased and positively correlated with osteoblast differentiation and bone formation under simulated microgravity environment. Furthermore, the gain of function of irisin in primary osteoblast differentiation under the simulated microgravity environment was confirmed after treatment with r-irisin. Lastly, we demonstrated the mechanism of $\mathrm{r}$-irisin preventing reduction of osteoblast differentiation induced by simulated microgravity through increasing $\beta$-catenin expression after treatment with $r$-irisin. Our finding may reveal a novel mechanism for osteoporosis induced by microgravity, and it provides a potential therapeutic strategy for the pathological musculoskeletal disorders. 


\section{Results}

\subsection{Simulated Microgravity Inhibits Irisin Precursor Expression, Bone Formation, and Osteoblast Differentiation}

In this study, the hind-limb unloading mice model was used to simulate microgravity effects on bone in vivo. Micro-computed tomograph (MicroCT) was used to analyze the structure and parameters (BMD, BV/TV) of distal femurs trabecular in hind-limb unloading mice and control mice. The results showed that simulated microgravity (SM) led to bone loss in mice femurs (Figure 1a). Moreover, the mineral apposition rates (MAR, bone formation-related parameter) of trabecular bone and cortical bone in hind-limb unloading mice femur were lower than those in the control group (Figure 1b). Importantly, not only were expressions of osteogenic genes such as alkaline phosphatase $(A l p)$ and collagen type I alpha 1 (ColI $\alpha 1$ ) respectively downregulated by $93.9 \%$ and $62.4 \%$, but the expression of Fndc5 (the irisin precursor) was also significantly decreased in tibias of hind-limb unloading mice compared to control mice in vivo (Figure 1c).

Distal femur of hind-limb unloading 3-month male mice (in vivo)
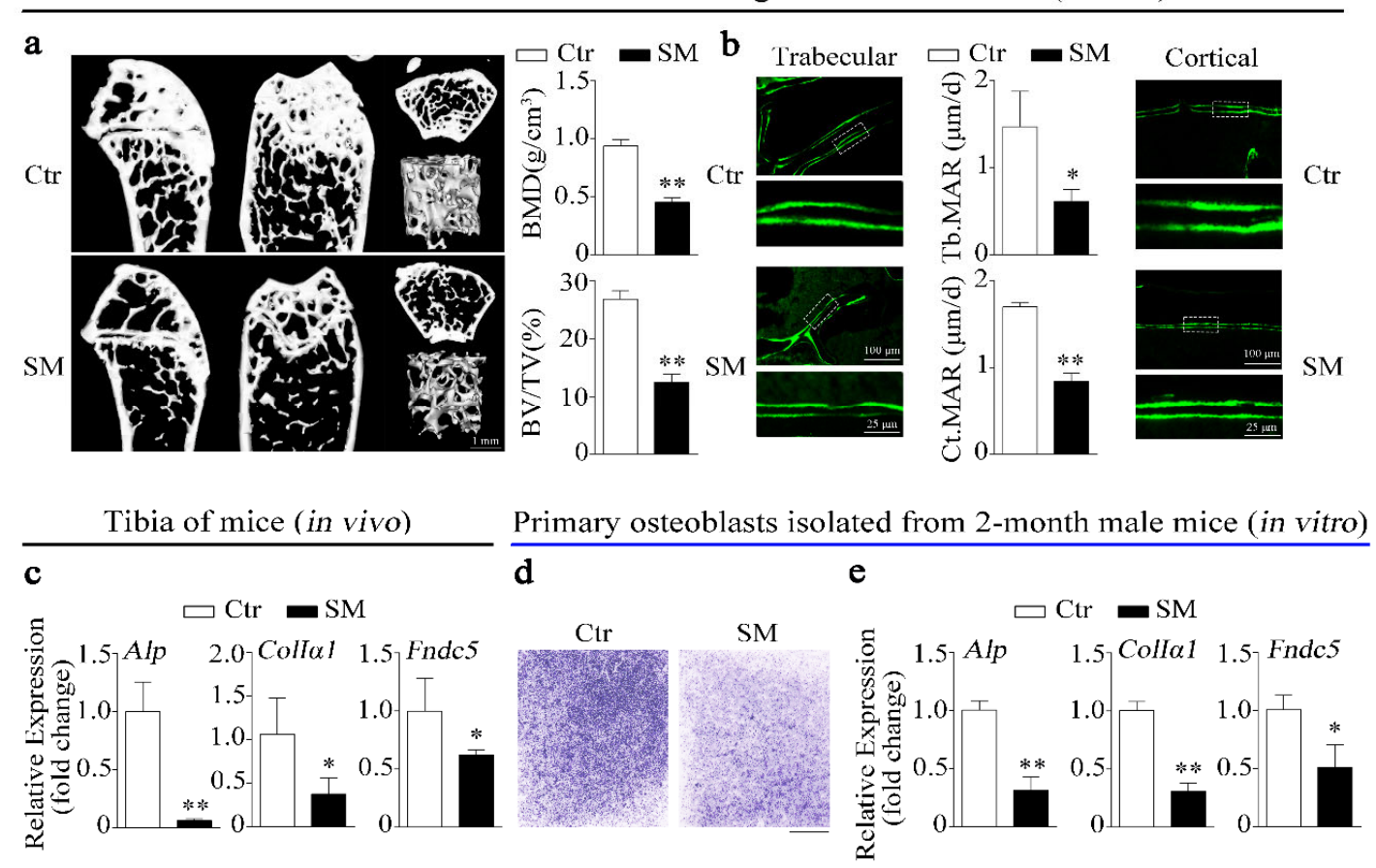

Figure 1. Irisin level, bone formation, and osteoblast differentiation were decreased under simulated microgravity in vivo and in vitro. (a) Representative images showing three-dimensional trabecular architecture in distal femur and microCT analysis of microstructural bone parameters of the distal femurs including BMD (bone mineral density) and BV/TV (bone volume to tissue volume) in control and hind-limb unloading mice group. Scale bar, $1 \mathrm{~mm} ; n=6$ mice per group. (b) Representative images showing new bone formation assessed and dynamic histomorphometric analysis of MAR (mineral apposition rate) by double calcein labeling in trabecular bone (left) and cortical bone (right) of distal femur from control and hind-limb unloading mice group. Upper scale bar, $100 \mu \mathrm{m}$; lower scale bar, $25 \mu \mathrm{m} ; n=6$ mice per group. (c) Real-time PCR analysis of Alp, Coll $\alpha 1$, and Fndc 5 expressions in tibias of control and hind-limb unloading mice for 28 days; $n=4$ mice per group. (d) Representative images of alkaline phosphatase (ALP) staining of primary osteoblasts cultured in random position machine for 48 h. Scale bar, $5 \mathrm{~mm}$. (e) Real-time PCR analysis of osteogenic gene Alp, Coll $\alpha 1$, and Fndc5 expressions in primary osteoblasts after random position machine (RPM) for $48 \mathrm{~h} ; n=3$. Gapdh was used as the internal control for messenger RNA (mRNA). Ctr: control, SM: simulated microgravity. All data are the mean $\pm \mathrm{SD}$. Statistical differences between the two groups were determined by the Student's $t$-test; ${ }^{*} p<0.05,{ }^{* *} p<0.01$. 
In vitro, we investigated the inhibitory effects of simulated microgravity (SM) on osteoblast differentiation using a random position machine (RPM) which rotated biological samples along two independent axes to change their orientation in random modes [6]. The images of ALP staining showed that the ALP activity of primary osteoblasts was inhibited under simulated microgravity condition (Figure 1d). Moreover, the expressions of Alp, ColI 1 1, and Fndc5 were also decreased by $68.7 \%, 68.9 \%$, and $48.8 \%$ in primary osteoblasts after RPM simulated microgravity treatment, respectively (Figure 1e). The preceding results suggest that irisin was insufficient under simulated microgravity and positively correlated with bone formation and osteoblast differentiation.

\section{2. $r$-Irisin Promotes Primary Osteoblast Differentiation}

To examine the function of irisin in regulating osteoblast differentiation, we treated primary osteoblasts with either different doses of recombinant irisin (r-irisin) or phosphate buffer saline (PBS). Real-time PCR results showed that $1 \mathrm{nM}$ and $10 \mathrm{nM}$ r-irisin could effectively increase osteogenic marker gene (Alp and ColI $\alpha 1$ ) mRNA levels, while $5 \mathrm{nM}$ r-irisin only slightly increased expressions of Alp $(9.4 \%)$ and Coll $\alpha 1$ (5.0\%). Furthermore, the increase for $1 \mathrm{nM}$ r-irisin was higher than that for $5 \mathrm{nM}$ and $10 \mathrm{nM}$ r-irisin (Figure 2a). In addition, ALP activity and mineralization are important marker steps of osteoblast differentiation; thus, we tested ALP activity and mineralized nodule formation of primary osteoblasts after treating with different doses of r-irisin. ALP-positive blue-violet complexes (upper) and Alizarin red-stained mineralized nodules (lower) were obviously increased in r-irisin groups (Figure 2b,c). All these results together indicated that different doses of r-irisin, especially lower doses of r-irisin $(1 \mathrm{nM})$, promoted primary osteoblast differentiation.

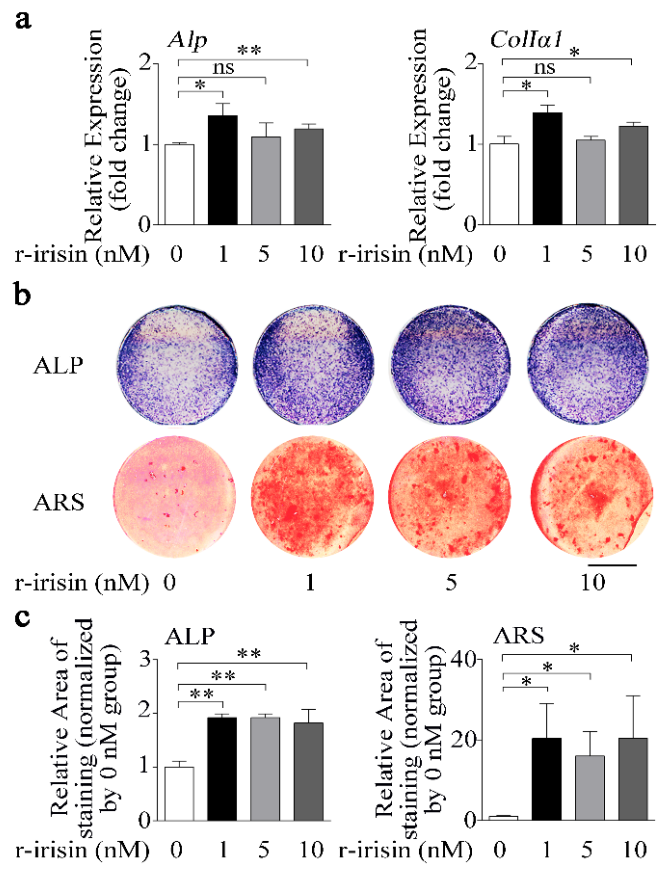

Figure 2. Lower dose of r-irisin promotes primary osteoblast differentiation. (a) Real-time PCR analysis of Alp and ColI $\alpha 1$ in primary osteoblasts after treatment with either different dose of r-irisin or PBS for $48 \mathrm{~h} ; n=3$. (b) Representative images of ALP staining (upper) and Alizarin red staining (ARS) (lower) in primary osteoblasts after treatment with either different dose of r-irisin or PBS for $48 \mathrm{~h}$ and $14 \mathrm{~d}$, respectively. Scale bar, $5 \mathrm{~mm}$. (c) Quantification of ALP (left) and ARS (right) staining areas in primary osteoblasts after treatment with treatment with either different dose of r-irisin or PBS for $48 \mathrm{~h}$ and $14 \mathrm{~d}$, respectively; $n=3$. Gapdh was used as the internal control for mRNA. All data are the mean \pm SD. Statistical differences between the two groups were determined by the Student's $t$-test; ${ }^{*} p<0.05$, ${ }^{* *} p<0.01, \mathrm{~ns}$, no significant difference. 


\subsection{Higher Dose of $r$-Irisin Promotes Primary Osteoblast Proliferation}

Not only does osteoblast differentiation indicate osteogenic activity, but osteoblast proliferation is also another important indicator of osteogenic effect. In order to demonstrate the exclusive role of r-irisin in osteoblast differentiation, the effect of r-irisin on osteoblast proliferation should be excluded. Therefore, we treated primary osteoblasts with different doses of either r-irisin or PBS, and found that the expressions of cell proliferation-related genes including cyclin families (CyclinA2, CyclinD1, and CyclinE1), and cyclin-dependent kinase families (CDK2 and CDK12) were gradually upregulated with the increase in r-irisin concentration (Figure 3a,b). Furthermore, the Cell Counting Kit-8 (CCK-8) assay was performed to test the effect of different doses of r-irisin on primary osteoblast proliferation. The value of optical density (OD) $450 \mathrm{~nm}$ in primary osteoblasts treated with $10 \mathrm{nM}$ r-irisin was obviously higher than other treatment groups at $48 \mathrm{~h}$ and $72 \mathrm{~h}$ (Figure 3c). From the above results (Figures 2 and 3), we found that a higher dose of r-irisin $(10 \mathrm{nM})$ promotes osteoblast differentiation and proliferation, but a lower dose of r-irisin $(1 \mathrm{nM})$ only promotes osteoblast differentiation, with no significant effects on osteoblast proliferation. Therefore, we chose a lower dose of r-irisin $(1 \mathrm{nM})$ to further investigate the gain of function of irisin on osteoblast differentiation under simulated microgravity condition.

a
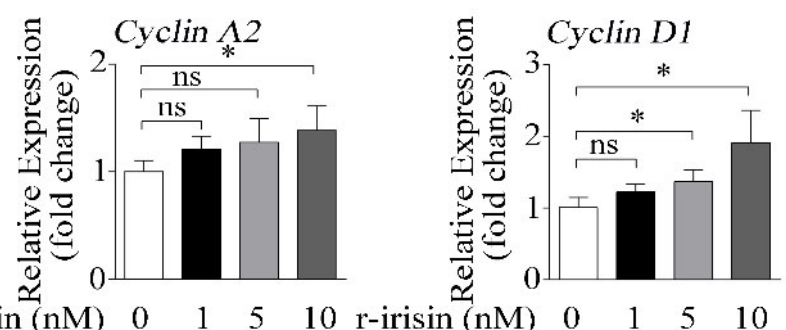

r

b

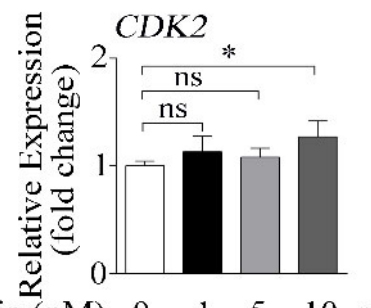

r-irisin $\stackrel{\not}{\text { (nM) }}$

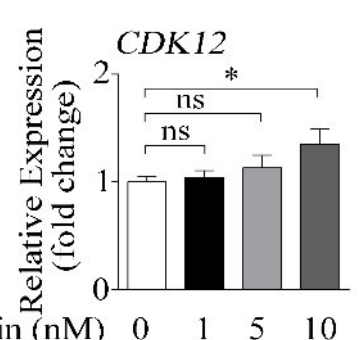

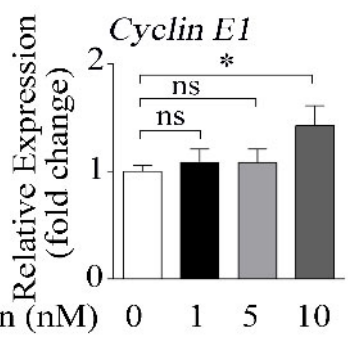

C

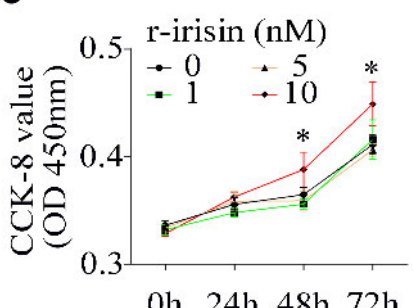

Figure 3. Higher dose of r-irisin promotes primary osteoblast proliferation. (a) Real-time PCR analysis of Cyclin A2, Cyclin D1, and Cyclin E1 in primary osteoblasts after treatment with a different dose of either r-irisin or PBS for $48 \mathrm{~h} ; n=3$. (b) Real-time PCR analysis of CDK2 and CDK12 in primary osteoblasts after treatment with a different dose of either r-irisin or PBS for $48 \mathrm{~h} ; n=3$. (c) Cell counting kit (CCK-8) was applied to detect proliferation in primary osteoblasts after treatment with a different dose of either r-irisin or PBS for 0, 24, 48, and $72 \mathrm{~h} ; n=5$. Gapdh was used as the internal control for mRNA. All data are the mean \pm SD. Statistical differences between the two groups were determined by the Student's $t$-test; ${ }^{*} p<0.05$, ns, no significant difference.

\section{4. r-Irisin Partly Prevents the Decrease of Osteoblast Differentiation Induced by Simulated Microgravity}

Due to irisin level being decreased under simulated microgravity condition (Figure 1), we added r-irisin $(1 \mathrm{nM})$ into primary osteoblasts prior to subjecting the cells to RPM-simulated microgravity for $48 \mathrm{~h}$. Osteogenic marker gene mRNA expressions and ALP activity were tested. After $48 \mathrm{~h}, \mathrm{r}$-irisin rescued the decrease of Alp and ColI $\alpha 1$ mRNA expressions induced by simulated microgravity $(p<$ 0.01, Figure 4a). In addition, the ALP staining results confirmed that reduction of ALP activity caused by simulated microgravity was also counteracted by r-irisin $(1 \mathrm{nM})$ in primary osteoblasts (Figure $4 \mathrm{~b}, \mathrm{c}$ ). 
The results indicated that r-irisin could partly prevent the decrease of primary osteoblast differentiation induced by simulated microgravity.

a

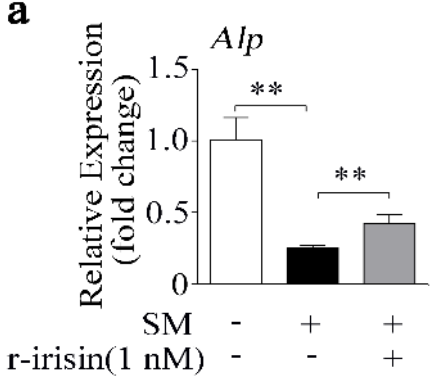

b

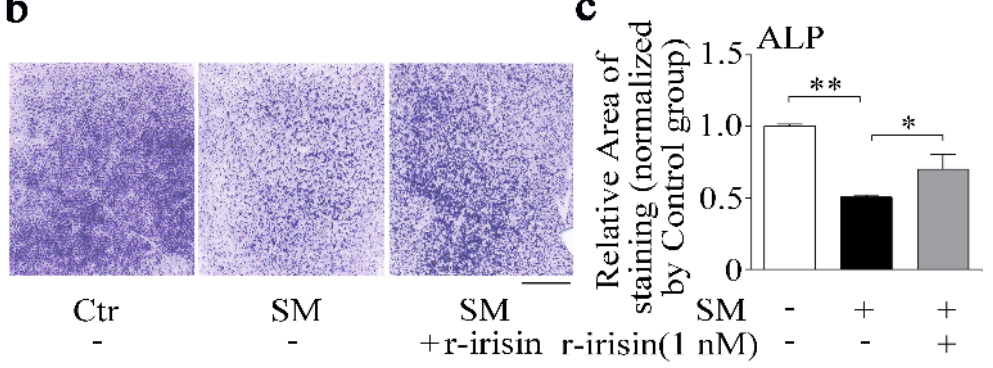

Figure 4. $r$-Irisin in part prevents the decrease of osteoblast differentiation induced by simulated microgravity. (a) Real-time PCR analysis of Alp and ColI $\alpha 1$ in primary osteoblasts after treatment with either $1 \mathrm{nM}$ r-irisin or PBS for $48 \mathrm{~h}$ under simulated microgravity; $n=3$. (b) Representative images of ALP staining of primary osteoblasts after treatment with either $1 \mathrm{nM} \mathrm{r}$-irisin or PBS for $48 \mathrm{~h}$ under simulated microgravity. Scale bar, $5 \mathrm{~mm}$. (c) Quantification of staining areas in primary osteoblasts after treatment with either $1 \mathrm{nM}$ r-irisin or PBS for $48 \mathrm{~h}$ under simulated microgravity; $n=3$. Gapdh was used as the internal control for mRNA. Ctr: control; SM: simulated microgravity. All data are the mean \pm SD. Statistical differences between the two groups were determined by the Student's $t$-test; ${ }^{*} p<0.05,{ }^{* *} p<0.01$.

\section{5. $r$-Irisin Promotes $\beta$-Catenin Expression to Regulate Osteoblast Differentiation under Simulated Microgravity Condition}

Irisin was reported to exert inhibitory effect on adipogenesis through regulating the $\mathrm{Wnt} / \beta$-catenin signaling pathway [37], which is a key signaling pathway in controlling osteoblast differentiation and bone formation [38]. Colaianni et al. demonstrated that $r$-irisin could increase $\beta$-catenin expression during differentiation of bone marrow stromal cells [27]. Therefore, we hypothesized that irisin might promote osteoblast differentiation through altering $\beta$-catenin expression. To investigate the role of irisin in $\beta$-catenin signaling, we treated primary osteoblasts with $1 \mathrm{nM}$ r-irisin. As shown in Figure $5 \mathrm{a}$, r-irisin significantly promoted mRNA and protein expressions of $\beta$-catenin. Moreover, $\beta$-catenin expression was downregulated under simulated microgravity in vivo and in vitro (Figure $5 b$ ). To further examine the role of $\beta$-catenin in osteoblast differentiation, $\beta$-catenin small interfering RNA (siRNA) (Si- $\beta$-cat) was used to knockdown $\beta$-catenin expression in osteoblast. Expressions of $\beta$-catenin and osteogenic marker genes (Alp and ColI $\alpha 1$ ) were downregulated by more than $50 \%$ after treatment with Si- $\beta$-cat, compared to treatment with siRNA negative control (Si-NC) $(p<0.01$, Figure $5 \mathrm{c})$. In addition, ALP staining results revealed that ALP activity was also suppressed by knockdown $\beta$-catenin (Figure $5 d$ ). $r$-Irisin promoted $\beta$-catenin expression which was decreased under simulated microgravity, and $\beta$-catenin also promoted osteoblast differentiation. Thus, we hypothesized that r-irisin might promote osteoblast differentiation through regulating $\beta$-catenin expression under simulated microgravity. We found that the decrease of $\beta$-catenin mRNA and protein levels induced by simulated microgravity was partly prevented by r-irisin (Figure $5 \mathrm{e}, \mathrm{f})$. 


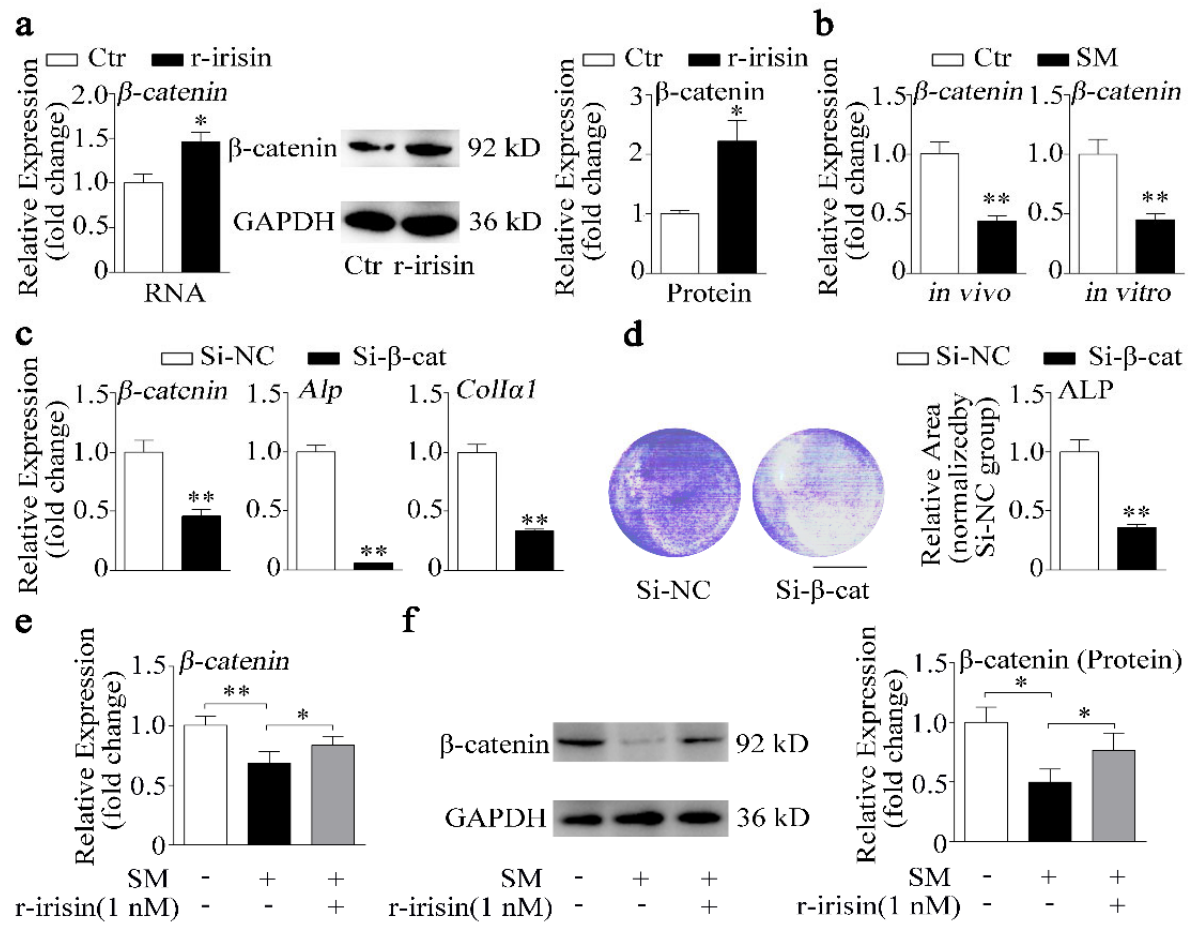

Figure 5. $r$-Irisin promotes $\beta$-catenin expression to regulate osteoblast differentiation under simulated microgravity condition. (a) Real-time PCR and Western blot analysis of $\beta$-catenin and quantification of $\beta$-catenin protein level in primary osteoblasts after treatment with either $1 \mathrm{nM}$ r-irisin or PBS for $48 \mathrm{~h} ; n$ = 3. (b) Real-time PCR analysis of $\beta$-catenin expression in tibias of control and hind-limb unloading mice for 28 days in vivo $(n=4)$ or in primary osteoblasts after random position machine for $48 \mathrm{~h}$ in vitro $(n=3)$. (c) Real-time PCR analysis of $\beta$-catenin, Alp, and ColI 1 expressions in MC3T3-E1 cells after treatment with either $\beta$-catenin small interfering RNA (siRNA) (Si- $\beta$-cat) or siRNA negative control (NC) (Si-NC) for $48 \mathrm{~h} ; n=3$. (d) Representative images of ALP staining and quantification of staining areas in MC3T3-E1 cells after treatment with either Si- $\beta$-cat or Si-NC for $48 \mathrm{~h}$. Scale bar, $5 \mathrm{~mm} ; n=3$.

(e) Real-time PCR analysis of $\beta$-catenin in primary osteoblasts after treatment with either $1 \mathrm{nM} \mathrm{r}$-irisin or PBS for $48 \mathrm{~h}$ under simulated microgravity; $n=3$. (f) Western blot analysis and quantification of $\beta$-catenin protein level in primary osteoblasts after treatment with either $1 \mathrm{nM} \mathrm{r}$-irisin or PBS for $48 \mathrm{~h}$ under simulated microgravity; $n=3$. Gapdh was used as the internal control for mRNA. Ctr: control; SM: simulated microgravity; Si- $\beta$-cat: $\beta$-catenin siRNA; Si-NC: siRNA NC. All data are the mean \pm SD. Statistical differences between the two groups were determined by the Student's $t$-test; ${ }^{*} p<0.05$, ** $p<0.01$.

\section{6. $\beta$-Catenin Overexpression Recovers Osteoblast Differentiation Reduction Induced by Simulated Microgravity}

We know that simulated microgravity inhibited irisin and $\beta$-catenin expression. Furthermore, $r$-irisin could partially counteract the reduction of osteoblast differentiation (Figure 4) and the decrease of $\beta$-catenin expression (Figure 5 ) induced by simulated microgravity. Hence, the effects of $\beta$-catenin on osteoblast differentiation under simulated microgravity should be further investigated. Osteoblasts were transfected with the pcDNA3.1- $\beta$-catenin plasmid ( $\beta$-cat) or blank pcDNA3.1 vector $(\mathrm{Vec})$ for $12 \mathrm{~h}$ and then exposed to RPM microgravity for $48 \mathrm{~h}$. $\beta$-Catenin mRNA and protein levels were partially rescued by the pcDNA3.1- $\beta$-catenin plasmid $(p<0.01$, Figure $6 a, b)$. The osteogenic marker gene (Alp and ColI $\alpha 1$ ) mRNA expressions and ALP activity were significantly decreased by simulated microgravity; nevertheless, the decrease was partially attenuated by the pcDNA3.1- $\beta$-catenin plasmid under simulated microgravity $(p<0.05$ or 0.01 , Figure $6 c, d)$. 

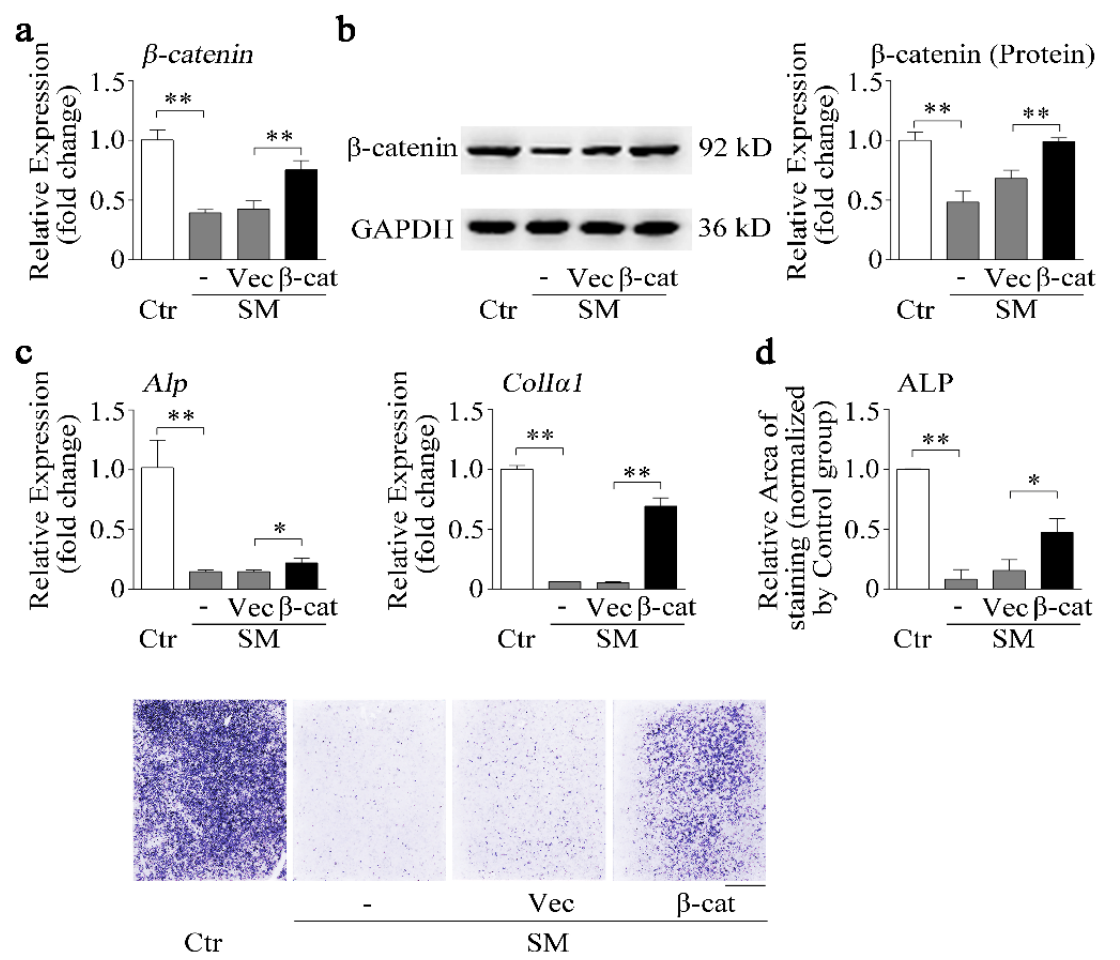

Figure 6. $\beta$-catenin overexpression recovers osteoblast differentiation reduction induced by simulated microgravity. (a) Real-time PCR analysis of $\beta$-catenin in MC3T3-E1 cells after treatment with either the pcDNA3.1- $\beta$-catenin plasmid ( $\beta$-cat) or pcDNA3.1 blank vector (Vec) under RPM simulated microgravity for $48 \mathrm{~h} ; n=3$. (b) Western blot analysis and quantification of $\beta$-catenin protein level in MC3T3-E1 cells after treatment with either the $\beta$-cat plasmid or blank vector under RPM simulated microgravity for $48 \mathrm{~h} ; n=3$. (c) Real-time PCR analysis of Alp and ColI $\alpha 1$ in MC3T3-E1 cells after treatment with the $\beta$-cat plasmid or blank vector under RPM simulated microgravity for $48 \mathrm{~h}$; $n=$ 3. (d) Representative images of ALP staining and quantification of staining areas in MC3T3-E1 cells after treatment with the $\beta$-cat plasmid or blank vector under RPM simulated microgravity for 48 h. Scale bar, $5 \mathrm{~mm}$. Gapdh was used as the internal control for mRNA. Ctr: control; SM: simulated microgravity; $\beta$-cat: pcDNA3.1- $\beta$-catenin plasmid; Vec: pcDNA3.1 blank vector. All data are the mean \pm SD. Statistical differences between the two groups were determined by the Student's $t$-test; * $p<0.05$, ** $p<0.01$.

Taken together, r-irisin counteracted osteoblast differentiation reduction induced by simulated microgravity in part through increasing $\beta$-catenin expression.

\section{Discussion}

Disuse osteoporosis is a common bone disease, which can be prevented by physical activity (exercise) [39]. Irisin, a novel exercise-induced myokine, was shown to stimulate osteoblast differentiation and bone formation [23-27]. Notably, the novel and most significant finding of this study is that we identified that irisin was downregulated under simulated microgravity and negatively correlated with bone formation and osteoblast differentiation in vivo and in vitro. Furthermore, r-irisin partly counteracted osteoblast differentiation reduction through increasing $\beta$-catenin expression under simulated microgravity. Our finding may reveal a novel mechanism for musculoskeletal crosstalk, and it provides a new therapeutic strategy for the pathological osteoporosis and muscle atrophy induced by microgravity.

Microgravity during spaceflight causes disruption of intracorporal bone homeostasis. Notably, there are precipitous declines (more than 10\%) in areal bone mineral density detected in the hip and spine in some long-duration astronauts that typically fly 180-day missions in space [40]. The hind-limb 
unloading mice model is widely used to simulate microgravity effects on the musculoskeletal system in vivo. Recent evidence suggests that musculoskeletal muscle talks to bone via a finely tuned network of molecules termed myokines, such as irisin [20]. In this study, we found that bone formation-related parameters (BMD, BV/TV, MAR) and osteogenic marker genes (Alp and ColI $\alpha 1$ ) were inhibited in hind-limb unloading mice. Furthermore, the expression of Fndc5 (irisin precursor) was also significantly downregulated in tibias of hind-limb unloading mice (Figure 1a-c). Kawao et al. demonstrated that Fndc 5 mRNA level was decreased in the soleus muscle of hind-limb unloading mice, and regression analysis revealed that the Fndc5 level of soleus muscle was positively related to tibia trabecular BMD [28]. The decrease of osteoblast differentiation is a key reason for bone loss induced by simulated microgravity. Fndc5 level was also decreased in primary osteoblasts under RPM simulated microgravity in vitro (Figure 1d,e). It is suggested that irisin may be as a musculoskeletal crosstalk regulator of bone formation and osteoblast differentiation under simulated microgravity.

Irisin, as an identified peptide hormone, is the cleavage product of Fndc5, released from myocytes into the bloodstream after physical exercise [20]. Irisin was reported to act as a link between muscles and other tissues or organs, especially for bone as a muscle neighboring tissue [20,23]. Colaianni's study demonstrated that a low cumulative weekly dose of r-irisin $(100 \mu \mathrm{g} / \mathrm{kg})$ was beneficial to young male mice cortical bone mass and bone bending strength [27]. Moreover, BMD of both the cortical and the trabecular bone volume fraction (BV/TV) was also prevented by r-irisin injection in hind-limb unloading mice [26]. Recent studies verified that irisin served as a positive regulator in osteoblast differentiation or proliferation $[24,25]$. In our study, we found that the osteogenic marker genes (Alp and ColI 1 1) and proliferation-related genes (CyclinA2, CyclinD1, CyclinE1, CDK2, and CDK12), ALP activity, and calcium deposition were increased after treatment with r-irisin in primary osteoblasts (Figures 2 and 3). Increasing evidence demonstrates that r-irisin effectively promoted the expressions of osteoblastic transcription regulators and osteoblast differentiation markers, ALP activity, and calcium deposition and proliferation in different osteogenic cells including calvaria primary osteoblasts [25], MC3T3-E1 cells [25,41,42], and bone marrow stromal cells (BMSCs) $[24,26,27]$. Our results indicated that r-irisin promoted primary osteoblast differentiation and proliferation, which is consistent with the above-reported studies. Under simulated microgravity condition, we found that the decrease of primary osteoblast differentiation was rescued by r-irisin in vitro (Figure 4). Furthermore, Colaianni et al. found that r-irisin not only prevented bone loss induced by hind-limb unloading in vivo, but also restored osteoblastogenesis in ex vivo cultures from unloaded mice [26]. These results suggest that r-irisin plays critical roles in osteoblast differentiation and bone formation under simulated microgravity environment.

To investigate the mechanism underlying how r-irisin increased osteoblast differentiation, we analyzed signaling pathways which irisin regulated based on reported studies, and found that irisin could modulate Notch [43], focal adhesion kinase (FAK) - extracellular signal-regulated kinase (Erk) - mitogen-activated protein (MAP) [23,25,44,45], reactive oxygen species (ROS) [46,47], phosphatidylinositol-3-kinase (PI3K) - v-akt murine thymoma viral oncogene homolog 1(AKT) [48], and $W n t / \beta$-catenin $[27,37,45]$ signaling pathways. Significantly, it is reported that irisin inhibited adipogenesis through regulating the Wnt/ $\beta$-catenin signaling pathway [37]. In addition, Wnt antagonists sclerostin and dickkopf- 1 were downregulated in MLO-Y4 cells after treatment with $\mathrm{r}$-irisin [45]. Interestingly, our data demonstrated that r-irisin promoted $\beta$-catenin mRNA and protein expression (Figure 5a). Colaianni et al. showed that $r$-irisin increased $\beta$-catenin expression during BMSC osteogenic differentiation [27]. Furthermore, the decrease of $\beta$-catenin expression caused by simulated microgravity was prevented by $r$-irsin in osteoblasts (Figure 5). This evidence strongly suggests that $r$-irisin promoted osteoblast differentiation in part depending on $\beta$-catenin.

Recently, canonical biochemical components such as the Wnt signaling pathway and $\beta$-catenin were reported to present mechanical sensitivity [49]. Previous studies showed that $W n t / \beta$-catenin signaling is a key signaling pathway in osteoblast differentiation and bone formation [33,50,51]. We also found that knockdown of $\beta$-catenin inhibited osteoblast differentiation in MC3T3-E1 cells (Figure 5c,d). 
In osteoblasts, mechanical stimulation causes a rapid, transient accumulation of active $\beta$-catenin in the cytoplasm and its translocation into the nucleus [34]. Furthermore, we reported that $\beta$-catenin reduction caused by simulated microgravity (Figure 5b) [14] and overexpression of $\beta$-catenin partially attenuated the negative effects of simulated microgravity on osteoblast differentiation (Figure 6). Thus, we wonder whether $\beta$-catenin acts as a mechano-mediator in the processing of $r$-irisin, by regulating osteoblast differentiation under simulated microgravity.

Overall, we demonstrated the possible mechanism of r-irisin, which promoted osteoblast differentiation under simulated microgravity. In detail, the irisin precursor was decreased under simulated microgravity, and r-irisin promoted osteoblast differentiation by increasing $\beta$-catenin expression. Moreover, $\mathrm{r}$-irisin or overexpression of $\beta$-catenin partially attenuated the negative effects of simulated microgravity on osteoblast differentiation in vitro. Our findings indicate that the mechanism of r-irisin involves controlling osteoblast differentiation, which may provide a novel therapy for the prevention of osteoporosis and other musculoskeletal disorders by microgravity. Furthermore, irisin can be stimulated by physical activity for the prevention and even future treatment of osteoporosis in genetic conditioning, which still requires further research. Moreover, it should be noted that irisin could promote osteoclast precursor cell proliferation but inhibit osteoclast differentiation [52], which was also altered by microgravity. The muscle-osteoblast-osteoclast crosstalk under microgravity might depend on irisin, which needs further elucidation.

\section{Materials and Methods}

\subsection{Hind-Limb Unloading Mice Model (Simulated Microgravity In Vivo)}

Two-month-old male Balb/c mice were purchased from the Laboratory Animal Center of the Fourth Military Medical University (Xi'an, Shanxi, China). The mice were kept for four weeks with hind limbs suspended. The hind limb suspension procedure was achieved by tail suspension as previously described [53]. In brief, mice were kept in standard cages with maintained suspension position at about a $30^{\circ}$ angle. This maneuver permitted the animals to have ad libitum access to food and water. The animal's overall appearance, drinking and eating habits, and tail were checked two times per day. All mice were injected intraperitoneally with green-fluorescent calcein (Sigma, St. Louis, MO, USA; $10 \mathrm{mg} / \mathrm{kg}$ body weight) in a time sequence of $10 \mathrm{~d}$ and $2 \mathrm{~d}$ before euthanasia. After euthanasia, experiments were conducted by harvesting bilateral femurs, which were processed for micro-computed tomography (microCT) and real-time PCR analysis ( $n=6$ mice per group). All the experimental procedures used in the present study were approved by the Animal Care and Experimental Safety of Northwestern Polytechnical University.

\subsection{Micro-Computed Tomography (microCT) Analysis}

Distal femurs were scanned with an eXplore Locus SP microCT device (General Electric, Milwaukee, WI, USA) at an isotropic resolution of $8 \mu \mathrm{m}$. Briefly, mice were anesthetized and sacrificed to isolate femurs without muscle and connective tissue, and cleaned femurs were fixed in $4 \%$ paraformaldehyde (PFA) and stored at $4{ }^{\circ} \mathrm{C}$. The scanning protocol was set as follows: X-ray source energy $80 \mathrm{kVp} / 80 \mu \mathrm{A}$, angle of increment $0.5^{\circ}$, exposure time $3000 \mathrm{~ms} /$ frame, scanning time $120 \mathrm{~min}$. Volumes of interest (VOIs) were selected for trabecular bone for each sample after three-dimensional (3D) reconstruction, in which trabecular VOIs were selected $0.5 \mathrm{~mm}$ above distal growth plate (indicated by coronal plane) at an axial height of $1.0 \mathrm{~mm}$, and the Advanced Bone Analysis Application (General Electric, Milwaukee, WI, USA) was used to calculate stereological parameters including bone mineral density (BMD) and bone volume to tissue volume (BV/TV) for trabecular microarchitecture. Detailed procedures and operations were performed according to published literature [54]. 


\subsection{RNA Extraction and Real-Time PCR}

Total RNA was used as a template for double-stranded complementary DNA (cDNA) synthesis (PrimeScript ${ }^{\mathrm{TM}}$ RT reagent Kit, Takara, Dalian, China). SYBR ${ }^{\circledR}$ Premix Ex Taq ${ }^{\mathrm{TM}}$ II (Takara, Dalian, China) was applied for the quantitative RT-PCR. Total RNA was extracted from individual samples of femurs or cells by means of TRIzol reagent (Invitrogen, Carlsbad, CA, USA). For mRNA, cDNA was reverse-transcribed using the PrimeScript RT reagent kit (TaKaRa, Dalian, China). Gene expression was then examined through real-time PCR with the SYBR Premix Ex Taq II kit (TaKaRa, Dalian, China), and real-time PCR analysis was performed using the Thermal Cycler C-1000 Touch system (BIO-RAD CFX Manager, Hercules, CA, USA). All amplifications were normalized to Gapdh. Data were analyzed using the comparative $\mathrm{Ct}$ method $\left(2^{-\Delta \Delta \mathrm{Ct}}\right)$ and expressed as fold change compared to corresponding control. All primer sequences are listed in Table 1.

Table 1. The primer sequences for real-time PCR.

\begin{tabular}{|c|c|c|}
\hline Gene Name & Forword $\left(5^{\prime}-3^{\prime}\right)$ & Reverse $\left(5^{\prime}-3^{\prime}\right)$ \\
\hline $\begin{array}{c}\text { Alp } \\
\text { (NM_007431.1) }\end{array}$ & GTTGCCAAGCTGGGAAGAACAC & CCСАССССGСТАТTCСАAАС \\
\hline $\begin{array}{c}\text { Colla1 } \\
\text { (NM_007742.3) }\end{array}$ & GAAGGCAACAGTCGATTCACC & GACTGTCTTGCCCCAAGTTCC \\
\hline $\begin{array}{c}\text { Fndc5 } \\
\text { (NM_027402.4) }\end{array}$ & GAGCCCAATAACAACAAGG & GAGGATAATAAGCCCGATG \\
\hline $\begin{array}{c}\text { Cyclin A2 } \\
\text { (NM_009828.3) }\end{array}$ & AGTACCTGCCTTCACTCATTGCTG & TCTGGTGAAGGTCCACAAGACAAG \\
\hline $\begin{array}{c}\text { Cyclin D1 } \\
\left(\mathrm{NM} \_007631.2\right)\end{array}$ & CAGCCСТGTTACCTGATACCT & TCCCAAGCACCTCATACTACC \\
\hline $\begin{array}{c}\text { Cyclin E1 } \\
\text { (NM_007633.2) }\end{array}$ & GCTTCGGGTCTGAGTTCCAA & GGATGAAAGAGCAGGGGTCC \\
\hline $\begin{array}{c}\text { CDK2 } \\
\text { (NM_016756.4) }\end{array}$ & TGTGCCTCCCCTGGATGAAG & CATCCTGGAAGAAAGGGTGA \\
\hline $\begin{array}{c}\text { CDK12 } \\
\text { (NM_026952.2) }\end{array}$ & CTGAATAACAGCGGGCAAAT & AGCTCTGGAGGTCGATACCA \\
\hline $\begin{array}{c}\beta \text {-catenin } \\
\text { (NM_007614.3) }\end{array}$ & ACGCTGCTCATCCСАCTAAT & AGTTCCGCGTCATCCTGATA \\
\hline $\begin{array}{c}\text { Gapdh } \\
\text { (NM_008084.2) }\end{array}$ & TGCACCACCAACTGCTTAG & GGATGCAGGGATGATGTTC \\
\hline
\end{tabular}

\subsection{Preparation of Primary Osteoblasts Isolated from Long Bone}

We prepared and cultured mouse primary osteoblasts according to previously reported protocols (Bone research protocol p22-23). Primary osteoblasts were isolated from the femurs of two-month-old male mice. Briefly, femurs without muscle and connective tissue had their bone marrow thoroughly flushed out with PBS, using a 5-mL syringe and a 27-gauge needle, before cutting the clean diaphyses into little pieces of approximately 1-2 mm using scissors. The bone pieces were washed several times with PBS, and incubated three times in $0.1 \%$ collagenase (Life Technologies, Carlsbad, CA, USA) and $0.25 \%$ trypsin (Life Technologies, Carlsbad, CA, USA) at $37^{\circ} \mathrm{C}$ in a shaking water bath in order to remove all remaining soft tissue and adherent cells, every $30 \mathrm{~min}$. From the fourth time to the seventh time, the cells were collected and cultured with alpha Modified Eagle's Medium ( $\alpha$-MEM) containing $10 \%$ fetal bovine serum (FBS, Corning, Steuben, NY, USA), and 1\% penicillin and streptomycin (Amresco, Fried, WA, USA). Medium was changed three times per week, and, after approximately 7-10 days, cells reached subconfluency, at which point they could be used for experiments.

\subsection{Cell Culture}

The primary osteoblasts were cultured in $\alpha$-MEM (Gibco, Carlsbad, CA, USA) supplemented with $10 \%$ FBS (Corning, Steuben, NY, USA), and 1\% penicillin and streptomycin (Amresco, Fried, WA, 
USA). The primary osteoblasts were maintained under standard cell culture conditions of $5 \% \mathrm{CO}_{2}$ and $95 \%$ humidity and were not used beyond six passages. For the experiments, confluent cells were removed using $0.25 \%$ trypsin containing $10 \mathrm{mM}$ ethylene diamine tetraacetic acid (EDTA). For the osteoblast differentiation experiment, primary osteoblasts were cultured in 24-well plates at $10^{5}$ cells per well with osteogenic medium containing 10\% FBS (Biological Industries, Migdal Haemek, Israel), $1 \%$ penicillin and streptomycin, $50 \mu \mathrm{g} / \mathrm{mL}$ of ascorbic acid, and $10 \mathrm{mM} \beta$-glycerophosphate.

The murine preosteoblast cell line MC3T3-E1 was generously provided by Dr. Hong Zhou of the University of Sydney. The MC3T3-E1 cells were cultured in $\alpha$-MEM (Gibco, Carlsbad, CA, USA) supplemented with 10\% FBS (Biological Industries, Migdal Haemek, Israel), and 1\% penicillin and streptomycin (Amresco, Fried, WA, USA). The cell cultures were incubated at a humidified, $37^{\circ} \mathrm{C}, 5 \%$ $\mathrm{CO}_{2}$ incubator.

\subsection{Random Positioning Machine (Simulated Microgravity In Vitro)}

A desktop random positioning machine (RPM, the Center for Space Science and Applied Research of Chinese Academy of Sciences) was used to simulate microgravity conditions for the cell culture, as described previously [6,7]. The cell culture vessel was fixed on the inner frame, and the RPM was placed inside a $37^{\circ} \mathrm{C}$ incubator. For simulated microgravity studies, cells were seeded at a density of 1 $\times 10^{4}$ cells $/ \mathrm{cm}^{2}$ on glass coverslips in a 90-mm dish and incubated at $37^{\circ} \mathrm{C}$. RPM culture flasks filled with growth medium (air bubbles avoided) were tightly capped and mounted in the inner frame of the RPM. The machine was operated in a random mode of speed $(0-8 \mathrm{rpm})$ and direction including both inner and outer frames for $48 \mathrm{~h}$. Cells of a static control group were cultured in the same $37^{\circ} \mathrm{C}$ incubator without rotation.

\subsection{Alkaline Phosphatase Staining}

Alkaline phosphatase (ALP) staining was performed with the BCIP/NBT alkaline phosphatase color development kit (Beyotime, Shanghai, China) according to the manufacturer's instruction [14,33]. Briefly, cells were carefully rinsed with PBS and fixed with neutral buffered formalin (10\%) for $15 \mathrm{~min}$. The fixed cells were rinsed with PBS again and then BCIP/NBT liquid substrate was added to each well. Finally, cells were washed with $\mathrm{ddH}_{2} \mathrm{O}$ after the color turning blue/purple. The stained cell cultures were imaged by a scanner.

\section{8. $r$-Irisin Treatment}

r-Irisin was purchased from Phoenix Pharmaceuticals Inc. (Burlingame, CA, USA), which was dissolved in sterile PBS. For osteoblast differentiation, primary osteoblasts were seeded in plates at a cell density of $2 \times 10^{4}$ cells/ $/ \mathrm{cm}^{2}$. The cells were cultured for 12 to $24 \mathrm{~h}$ to reach $80 \%-90 \%$ confluency, at which time different doses of r-irisin were added. The osteogenic medium with r-irisin was changed every two days.

For osteoblast proliferation, primary osteoblasts were seeded in 12-well plates at a cell density of $4 \times 10^{4}$ cells per well. The cells were cultured for 12 to $24 \mathrm{~h}$ to reach $40 \%-50 \%$ confluency, at which time the different doses of r-irisin were added. The cells were collected for real-time PCR analysis.

\subsection{Alizarin Red Staining}

Cells were fixed with neutral buffered formalin $(10 \%)$ for $15 \mathrm{~min}$. The fixed cells were rinsed with PBS and stained with 0.5\% Alizarin red s (Sigma-Aldrich, St. Louis, MO, USA) solution ( $\mathrm{pH} 4.2$ ) for $15 \mathrm{~min}$ at room temperature. After being washed with $\mathrm{ddH}_{2} \mathrm{O}$ on a shaking platform four times, $5 \mathrm{~min} /$ time, the mineralized nodules were imaged by a scanner. 


\subsection{Cell Proliferation Assay}

Cell proliferation activity was measured using the Cell Counting Kit-8 (CCK-8) (Biosharp, Shanghai, China). The primary osteoblasts were seeded in 96-well plates at a cell density of 2000 cells with $100 \mu \mathrm{L}$ medium per well. After adherence, the cells were added with different doses of r-irisin or PBS, then cultured for $0,1,2$, and $3 \mathrm{~d}$ with drug. Next, $10 \mu \mathrm{L}$ of CCK-8 solution was added into each well, followed by incubation with cells for $1 \mathrm{~h}$. The absorbance was recorded at $450 \mathrm{~nm}$. All groups performed at least five replicates.

\subsection{Western Blot Analysis}

Cells were lysed in Cell Lysis Buffer for Western and IP (Beyotime, Shanghai, China) supplemented with 1\% Protease inhibitor Cocktail Set III (Calbiochem, Darmstadt, Germany) on ice. Protein fractions were collected by centrifugation at $15,000 \times g, 4{ }^{\circ} \mathrm{C}$, for $5 \mathrm{~min}$ and subjected to SDS-PAGE, before being transferred to NC membranes (PALL, Port Washington, NY, USA). The membranes were blocked with $5 \%$ skim milk and incubated with specific antibodies overnight at $4{ }^{\circ} \mathrm{C}$. HRP-labeled secondary antibody (CoWin Bioscience, Beijing, China) was added and then visualized using a Chemiluminescence Detection System (Promega, Madison, WI, USA) as recommended by the manufacturer. The following primary antibodies were used: $\beta$-catenin Rabbit polyclonal antibody (pAb) (1:1000, Cell Signaling Technology, Danvers, MA, USA) and glyceraldehyde 3-phosphate dehydrogenase (GAPDH) Rabbit pAb (1:1000, Servicebio, Wuhan, China).

\subsection{Cell Transfection}

MC3T3-E1 cells were seeded at cell density of $1 \times 10^{4}$ cells $/ \mathrm{cm}^{2}$ until cultured to reach $80 \%-90 \%$ confluency. Then, the cells were transfected with $100 \mathrm{nM} \beta$-catenin siRNA (si- $\beta$-cat) by Lipofectamine 2000 (invitrogen, Carlsbad, CA, USA). After transfection for $6 \mathrm{~h}$, serum-free medium was replaced by growth medium. MC3T3-E1 cells were harvested for real-time PCR analysis and alkaline phosphatase staining after $48 \mathrm{~h}$. $\beta$-Catenin siRNA (Ribobio, Guangzhou, China) sequences were 5'-CAAGCCUUAGUAAACAUAAdTdT-3' (positive-sense strand) and 3'-dTdTGUUCGGAAUCAUUUGUAUU-5' (antisense strand).

For simulated microgravity studies, MC3T3-E1 cells were seeded at a density of $1 \times 10^{4} \mathrm{cells} / \mathrm{cm}^{2}$ on glass coverslips in a $90-\mathrm{mm}$ dish and incubated at $37{ }^{\circ} \mathrm{C}$. Cells were cultured until to reach $80 \%-90 \%$ confluency and then transfected with $2 \mu \mathrm{g} / \mathrm{mL}$ pcDNA3.1- $\beta$-catenin plasmid by Lipofectamine 2000 (invitrogen, Carlsbad, CA, USA). After transfection for $6 \mathrm{~h}$, serum-free medium was replaced by the growth medium. After $12 \mathrm{~h}$, cells were transferred to RPM culture flasks. The blank pcDNA3.1 plasmid was used as a negative control plasmid.

\subsection{Statistical Analysis}

All numerical data were expressed as the mean \pm SD. All experiments were performed with at least three replicates. Statistically significant differences were analyzed using Student's $t$-test with the statistical software Prism (GraphPad Software Inc, La Jolla, CA, USA). A value of $p<0.05$ was considered significant in all cases $\left({ }^{*} p<0.05,{ }^{* *} p<0.01\right)$.

Author Contributions: Conceptualization, Z.C. and A.Q.; data curation, Z.C. and Y.Z.; formal analysis, Z.C. and F.Z.; funding acquisition, Z.C., X.L., Y.T., L.H., Y.L. and A.Q.; investigation, Z.C., Y.Z., F.Z., and S.L.; methodology, Z.C., Y.Z., F.Z., C.Y. (Chong Yin) and C.Y. (Chaofei Yang); project administration, Z.C., Y.L. and A.Q.; resources, Z.C., Y.Z., C.Y. (Chong Yin), C.Y. (Chaofei Yang), X.W., Z.W., D.L. and A.Q.; software, Z.C.; supervision, Z.C., X.L., Y.T., L.H., Y.L. and A.Q.; validation, A.Q.; visualization, A.Q.; writing-original draft, Z.C. and A.Q.; writing-review and editing, L.H., Y.L. and A.Q. All authors have read and agreed to the published version of the manuscript.

Funding: This work was supported by the Natural Science Foundation of China (31570940, 81772017, 31400725, 81700784, 81872129, and 81801871), the Innovation Foundation for Doctor Dissertation of Northwestern Polytechnical University (CX201821), the China Postdoctoral Science Foundation (2018T111099, 2017M610653), the Fundamental Research Funds for the Central Universities (3102018zy053), the Shenzhen Science and Technology 
Project (JCYJ20160229174320053), and the Project Supported by Natural Science Basic Research Plan in Shaanxi Province of China (2018JM3040).

Acknowledgments: The authors would like to thank Hong Zhou (The University of Sydney, Australia) for generously providing the MC3T3-E1 cell line.

Conflicts of Interest: The authors declare no conflicts of interest. The funders had no role in the design of the study; in the collection, analyses, or interpretation of data; in the writing of the manuscript, or in the decision to publish the results.

\section{Abbreviations}

\begin{tabular}{|c|c|}
\hline $\mathrm{AKT}$ & v-akt murine thymoma viral oncogene homolog 1 \\
\hline ALP/Alp & alkaline phosphatase \\
\hline ARS & Alizarin red staining \\
\hline BMSCs & bone marrow stromal cells \\
\hline BMD & bone mineral density \\
\hline BMP & bone morphogenetic protein \\
\hline $\mathrm{BV} / \mathrm{TV}$ & bone volume to tissue volume (bone volume fraction) \\
\hline CCK-8 & Cell Counting Kit-8 \\
\hline CDK2 & cyclin-dependent kinase 2 \\
\hline CDK12 & cyclin-dependent kinase 12 \\
\hline Ctr & control \\
\hline Coll $\alpha 1$ & collagen type 1 alpha- 1 \\
\hline EDTA & ethylene diamine tetraacetic acid \\
\hline Erk & extracellular signal-regulated kinase \\
\hline FAK & focal adhesion kinase \\
\hline FBS & fetal bovine serum \\
\hline FNDC5/Fndc5 & fibronectin type III domain-containing 5 \\
\hline Gapdh/GAPDH & glyceraldehyde 3-phosphate dehydrogenase \\
\hline MAP & mitogen-activated protein \\
\hline MAR & mineral apposition rate \\
\hline microCT & micro-computed tomography \\
\hline $\mathrm{NC}$ & negative control \\
\hline OD & optical density \\
\hline $\mathrm{pAb}$ & Polyclonal antibody \\
\hline PBS & phosphate buffer saline \\
\hline PFA & paraformaldehyde \\
\hline PI3K & phosphatidylinositol-3 kinase \\
\hline r-irisin & recombinant irisin \\
\hline ROS & reactive oxygen species \\
\hline RPM & random position machine \\
\hline SM & simulated microgravity \\
\hline Si- $\beta$-cat & $\beta$-catenin siRNA \\
\hline Si-NC & siRNA NC \\
\hline Vec & pcDNA3.1 blank vector \\
\hline Wnt & wingless-type MMTV integration site family \\
\hline$\alpha$-MEM & alpha Modified Eagle's Medium \\
\hline$\beta$-cat & pcDNA3.1- $\beta$-catenin plasmid \\
\hline
\end{tabular}

\section{References}

1. Cao, Q.; Zhang, J.; Liu, H.; Wu, Q.; Chen, J.; Chen, G.Q. The mechanism of anti-osteoporosis effects of 3-hydroxybutyrate and derivatives under simulated microgravity. Biomaterials 2014, 35, 8273-8283. [CrossRef] 
2. Cristofaro, F.; Pani, G.; Pascucci, B.; Mariani, A.; Balsamo, M.; Donati, A.; Mascetti, G.; Rea, G.; Rizzo, A.M.; Visai, L. The NATO project: nanoparticle-based countermeasures for microgravity-induced osteoporosis. Sci. Rep. 2019, 9, 17141. [CrossRef] [PubMed]

3. Hemmatian, H.; Bakker, A.D.; Klein-Nulend, J.; van Lenthe, G.H. Aging, Osteocytes, and Mechanotransduction. Curr. Osteoporos. Rep. 2017, 15, 401-411. [CrossRef]

4. Eimori, K.; Endo, N.; Uchiyama, S.; Takahashi, Y.; Kawashima, H.; Watanabe, K. Disrupted Bone Metabolism in Long-Term Bedridden Patients. Plos ONE 2016, 11, e0156991. [CrossRef]

5. Orwoll, E.S.; Adler, R.A.; Amin, S.; Binkley, N.; Lewiecki, E.M.; Petak, S.M.; Shapses, S.A.; Sinaki, M.; Watts, N.B.; Sibonga, J.D. Skeletal health in long-duration astronauts: nature, assessment, and management recommendations from the NASA Bone Summit. J. Bone Miner. Res. 2013, 28, 1243-1255. [CrossRef]

6. Chen, Z.H.; Zhao, F.; Qi, Y.D.; Hu, L.F.; Li, D.J.; Yin, C.; Su, P.H.; Zhang, Y.; Ma, J.H.; Qian, J.; et al. Simulated microgravity alters the expression of cytoskeleton- and ATP-binding-related genes in MLO-Y4 osteocytes. Acta Astronaut. 2016, 129, 186-192. [CrossRef]

7. Jian, J.; Sun, L.; Cheng, X.; Hu, X.; Liang, J.; Chen, Y. Calycosin-7-O-beta-d-glucopyranoside stimulates osteoblast differentiation through regulating the BMP/WNT signaling pathways. Acta Pharm. Sin. B 2015, 5, 454-460. [CrossRef] [PubMed]

8. Diao, Y.; Chen, B.; Wei, L.; Wang, Z. Polyphenols (S3) Isolated from Cone Scales of Pinus koraiensis Alleviate Decreased Bone Formation in Rat under Simulated Microgravity. Sci. Rep. 2018, 8, 12719. [CrossRef] [PubMed]

9. Salingcarnboriboon, R.; Tsuji, K.; Komori, T.; Nakashima, K.; Ezura, Y.; Noda, M. Runx2 is a target of mechanical unloading to alter osteoblastic activity and bone formation in vivo. Endocrinology 2006, 147, 2296-2305. [CrossRef] [PubMed]

10. Zhou, Z.; Shi, G.; Zheng, X.; Jiang, S.; Jiang, L. Autophagy activation facilitates mechanical stimulation-promoted osteoblast differentiation and ameliorates hindlimb unloading-induced bone loss. Biochem. Biophys. Res. Commun. 2018, 498, 667-673. [CrossRef] [PubMed]

11. Kumei, Y.; Shimokawa, H.; Katano, H.; Hara, E.; Akiyama, H.; Hirano, M.; Mukai, C.; Nagaoka, S.; Whitson, P.A.; Sams, C.F. Microgravity induces prostaglandin E2 and interleukin-6 production in normal rat osteoblasts: role in bone demineralization. J. Biotechnol. 1996, 47, 313-324. [CrossRef]

12. Guo, B.; Zhang, Z.K.; Liang, C.; Li, J.; Liu, J.; Lu, A.; Zhang, B.T.; Zhang, G. Molecular Communication from Skeletal Muscle to Bone: A Review for Muscle-Derived Myokines Regulating Bone Metabolism. Calcif. Tissue Int. 2017, 100, 184-192. [CrossRef] [PubMed]

13. Camirand, A.; Goltzman, D.; Gupta, A.; Kaouass, M.; Panda, D.; Karaplis, A. The Role of Parathyroid Hormone-Related Protein (PTHrP) in Osteoblast Response to Microgravity: Mechanistic Implications for Osteoporosis Development. Plos ONE 2016, 11, e0160034. [CrossRef] [PubMed]

14. Yin, C.; Zhang, Y.; Hu, L.; Tian, Y.; Chen, Z.; Li, D.; Zhao, F.; Su, P.; Ma, X.; Zhang, G.; et al. Mechanical unloading reduces microtubule actin crosslinking factor 1 expression to inhibit beta-catenin signaling and osteoblast proliferation. J. Cell. Physiol. 2018, 233, 5405-5419. [CrossRef]

15. Qian, X.; Zhang, C.; Chen, G.; Tang, Z.; Liu, Q.; Chen, J.; Tong, X.; Wang, J. Effects of BMP-2 and FGF2 on the osteogenesis of bone marrow-derived mesenchymal stem cells in hindlimb-unloaded rats. Cell Biochem. Biophys. 2014, 70, 1127-1136. [CrossRef]

16. Lloyd, S.A.; Lang, C.H.; Zhang, Y.; Paul, E.M.; Laufenberg, L.J.; Lewis, G.S.; Donahue, H.J. Interdependence of muscle atrophy and bone loss induced by mechanical unloading. J. Bone Miner. Res. 2014, 29, 1118-1130. [CrossRef]

17. Keyak, J.H.; Koyama, A.K.; LeBlanc, A.; Lu, Y.; Lang, T.F. Reduction in proximal femoral strength due to long-duration spaceflight. Bone 2009, 44, 449-453. [CrossRef]

18. Karsenty, G.; Mera, P. Molecular bases of the crosstalk between bone and muscle. Bone 2018, 115, 43-49. [CrossRef]

19. Colaianni, G.; Cinti, S.; Colucci, S.; Grano, M. Irisin and musculoskeletal health. Ann. New York Acad. Sci. 2017, 1402, 5-9. [CrossRef]

20. Colaianni, G.; Sanesi, L.; Storlino, G.; Brunetti, G.; Colucci, S.; Grano, M. Irisin and Bone: From Preclinical Studies to the Evaluation of Its Circulating Levels in Different Populations of Human Subjects. Cells 2019, 8, 451. [CrossRef] 
21. Gao, S.; Cheng, Y.; Zhao, L.; Chen, Y.; Liu, Y. The relationships of irisin with bone mineral density and body composition in PCOS patients. Diabetes/Metab. Res. 2016, 32, 421-428. [CrossRef] [PubMed]

22. Wu, L.F.; Zhu, D.C.; Tang, C.H.; Ge, B.; Shi, J.; Wang, B.H.; Lu, Y.H.; He, P.; Wang, W.Y.; Lu, S.Q.; et al. Association of Plasma Irisin with Bone Mineral Density in a Large Chinese Population Using an Extreme Sampling Design. Calcif. Tissue Int. 2018, 103, 246-251. [CrossRef] [PubMed]

23. Kim, H.; Wrann, C.D.; Jedrychowski, M.; Vidoni, S.; Kitase, Y.; Nagano, K.; Zhou, C.; Chou, J.; Parkman, V.A.; Novick, S.J.; et al. Irisin Mediates Effects on Bone and Fat via alphaV Integrin Receptors. Cell 2018, 175, 1756-1768 e1717. [CrossRef] [PubMed]

24. Colaianni, G.; Cuscito, C.; Mongelli, T.; Oranger, A.; Mori, G.; Brunetti, G.; Colucci, S.; Cinti, S.; Grano, M. Irisin enhances osteoblast differentiation in vitro. Int. J. Endocrinol. 2014, 2014, 902186. [CrossRef]

25. Qiao, X.; Nie, Y.; Ma, Y.; Chen, Y.; Cheng, R.; Yin, W.; Hu, Y.; Xu, W.; Xu, L. Irisin promotes osteoblast proliferation and differentiation via activating the MAP kinase signaling pathways. Sci. Rep. 2016, 6, 18732. [CrossRef]

26. Colaianni, G.; Mongelli, T.; Cuscito, C.; Pignataro, P.; Lippo, L.; Spiro, G.; Notarnicola, A.; Severi, I.; Passeri, G.; Mori, G.; et al. Irisin prevents and restores bone loss and muscle atrophy in hind-limb suspended mice. Sci. Rep. 2017, 7, 2811. [CrossRef]

27. Colaianni, G.; Cuscito, C.; Mongelli, T.; Pignataro, P.; Buccoliero, C.; Liu, P.; Lu, P.; Sartini, L.; Di Comite, M.; Mori, G.; et al. The myokine irisin increases cortical bone mass. Proc. Natl. Acad. Sci. United States Am. 2015, 112, 12157-12162. [CrossRef]

28. Kawao, N.; Moritake, A.; Tatsumi, K.; Kaji, H. Roles of Irisin in the Linkage from Muscle to Bone During Mechanical Unloading in Mice. Calcif. Tissue Int. 2018, 103, 24-34. [CrossRef]

29. Jo, S.; Yoon, S.; Lee, S.Y.; Kim, S.Y.; Park, H.; Han, J.; Choi, S.H.; Han, J.S.; Yang, J.H.; Kim, T.H. DKK1 Induced by 1,25D3 Is Required for the Mineralization of Osteoblasts. Cells 2020, 9, 236. [CrossRef]

30. Sen, B.; Paradise, C.R.; Xie, Z.; Sankaran, J.; Uzer, G.; Styner, M.; Meyer, M.; Dudakovic, A.; van Wijnen, A.J.; Rubin, J. beta-catenin preserves the stem state of murine bone marrow stromal cells through activation of EZH2. J. Bone Miner. Res. 2020. [CrossRef]

31. Shen, G.; Ren, H.; Shang, Q.; Zhao, W.; Zhang, Z.; Yu, X.; Tang, K.; Tang, J.; Yang, Z.; Liang, D.; et al. Foxf1 knockdown promotes BMSC osteogenesis in part by activating the Wnt/beta-catenin signalling pathway and prevents ovariectomy-induced bone loss. EBioMedicine 2020, 52, 102626. [CrossRef] [PubMed]

32. Yu, A.X.; Xu, M.L.; Yao, P.; Kwan, K.K.; Liu, Y.X.; Duan, R.; Dong, T.T.; Ko, R.K.; Tsim, K.W. Corylin, a flavonoid derived from Psoralea Fructus, induces osteoblastic differentiation via estrogen and Wnt/beta-catenin signaling pathways. Faseb J. Off. Publ. Fed. Am. Soc. Exp. Biol. 2020. [CrossRef]

33. Zhang, Y.; Yin, C.; Hu, L.; Chen, Z.; Zhao, F.; Li, D.; Ma, J.; Ma, X.; Su, P.; Qiu, W.; et al. MACF1 Overexpression by Transfecting the $21 \mathrm{kbp}$ Large Plasmid PEGFP-C1A-ACF7 Promotes Osteoblast Differentiation and Bone Formation. Hum. Gene Ther. 2018, 29, 259-270. [CrossRef] [PubMed]

34. Sen, B.; Styner, M.; Xie, Z.H.; Case, N.; Rubin, C.T.; Rubin, J. Mechanical Loading Regulates NFATc1 and beta-Catenin Signaling through a GSK3 beta Control Node. J. Biol. Chem. 2009, 284, 34607-34617. [CrossRef]

35. Case, N.; Ma, M.; Sen, B.; Xie, Z.; Gross, T.S.; Rubin, J. Beta-catenin levels influence rapid mechanical responses in osteoblasts. J. Biol. Chem. 2008, 283, 29196-29205. [CrossRef]

36. Lin, C.; Jiang, X.; Dai, Z.; Guo, X.; Weng, T.; Wang, J.; Li, Y.; Feng, G.; Gao, X.; He, L. Sclerostin mediates bone response to mechanical unloading through antagonizing Wnt/beta-catenin signaling. J. Bone Miner. Res. Off. J. Am. Soc. Bone Miner. Res. 2009, 24, 1651-1661. [CrossRef]

37. Ma, E.B.; Sahar, N.E.; Jeong, M.; Huh, J.Y. Irisin Exerts Inhibitory Effect on Adipogenesis Through Regulation of Wnt Signaling. Front. Physiol. 2019, 10, 1085. [CrossRef]

38. Baron, R.; Kneissel, M. WNT signaling in bone homeostasis and disease: from human mutations to treatments. Nat. Med. 2013, 19, 179-192. [CrossRef]

39. Yuan, Y.; Chen, X.; Zhang, L.; Wu, J.; Guo, J.; Zou, D.; Chen, B.; Sun, Z.; Shen, C.; Zou, J. The roles of exercise in bone remodeling and in prevention and treatment of osteoporosis. Prog. Biophys. Mol. Biol. 2016, 122, 122-130. [CrossRef]

40. Sibonga, J.D. Spaceflight-induced bone loss: is there an osteoporosis risk? Curr. Osteoporos. Rep. 2013, 11, 92-98. [CrossRef]

41. Zeng, R.; Ma, Y.; Qiao, X.; Zhang, J.; Luo, Y.; Li, S.; Liu, L.; Xu, L. The effect of His-tag and point mutation on the activity of irisin on MC3T3-E1 cells. Biosci. Trends 2018, 12, 580-586. [CrossRef] [PubMed] 
42. Zhang, D.; Bae, C.; Lee, J.; Lee, J.; Jin, Z.; Kang, M.; Cho, Y.S.; Kim, J.H.; Lee, W.; Lim, S.K. The bone anabolic effects of irisin are through preferential stimulation of aerobic glycolysis. Bone 2018, 114, 150-160. [CrossRef] [PubMed]

43. Jin, Z.; Guo, P.; Li, X.; Ke, J.; Wang, Y.; Wu, H. Neuroprotective effects of irisin against cerebral ischemia/ reperfusion injury via Notch signaling pathway. Biomed. Pharmacother. 2019, 120, 109452. [CrossRef] [PubMed]

44. Zhang, Y.; Li, R.; Meng, Y.; Li, S.; Donelan, W.; Zhao, Y.; Qi, L.; Zhang, M.; Wang, X.; Cui, T.; et al. Irisin stimulates browning of white adipocytes through mitogen-activated protein kinase p38 MAP kinase and ERK MAP kinase signaling. Diabetes 2014, 63, 514-525. [CrossRef]

45. Storlino, G.; Colaianni, G.; Sanesi, L.; Lippo, L.; Brunetti, G.; Errede, M.; Colucci, S.; Passeri, G.; Grano, M. Irisin Prevents Disuse-Induced Osteocyte Apoptosis. J. Bone Miner. Res. 2019. [CrossRef]

46. Chen, R.R.; Fan, X.H.; Chen, G.; Zeng, G.W.; Xue, Y.G.; Liu, X.T.; Wang, C.Y. Irisin attenuates angiotensin II-induced cardiac fibrosis via Nrf2 mediated inhibition of ROS/ TGFbeta1/Smad2/3 signaling axis. Chem. -Biol. Interact. 2019, 302, 11-21. [CrossRef]

47. Deng, X.; Huang, W.; Peng, J.; Zhu, T.T.; Sun, X.L.; Zhou, X.Y.; Yang, H.; Xiong, J.F.; He, H.Q.; Xu, Y.H.; et al. Irisin Alleviates Advanced Glycation End Products-Induced Inflammation and Endothelial Dysfunction via Inhibiting ROS-NLRP3 Inflammasome Signaling. Inflammation 2018, 41, 260-275. [CrossRef]

48. Zhang, D.; Zhang, P.; Li, L.; Tang, N.; Huang, F.; Kong, X.; Tan, X.; Shi, G. Irisin functions to inhibit malignant growth of human pancreatic cancer cells via downregulation of the PI3K/AKT signaling pathway. Oncotargets Ther. 2019, 12, 7243-7249. [CrossRef]

49. Xin, M.; Yang, Y.; Zhang, D.; Wang, J.; Chen, S.; Zhou, D. Attenuation of hind-limb suspension-induced bone loss by curcumin is associated with reduced oxidative stress and increased vitamin D receptor expression. Osteoporos. Int. A J. Establ. Result Coop. Between Eur. Found. Osteoporos. Natl. Osteoporos. Found. USA 2015, 26, 2665-2676. [CrossRef]

50. Hu, L.; Su, P.; Yin, C.; Zhang, Y.; Li, R.; Yan, K.; Chen, Z.; Li, D.; Zhang, G.; Wang, L.; et al. Microtubule actin crosslinking factor 1 promotes osteoblast differentiation by promoting beta-catenin/TCF1/Runx2 signaling axis. J. Cell. Physiol. 2018, 233, 1574-1584. [CrossRef]

51. Kim, H.Y.; Yoon, J.Y.; Yun, J.H.; Cho, K.W.; Lee, S.H.; Rhee, Y.M.; Jung, H.S.; Lim, H.J.; Lee, H.; Choi, J.; et al. CXXC5 is a negative-feedback regulator of the Wnt/beta-catenin pathway involved in osteoblast differentiation. Cell Death Differ. 2015, 22, 912-920. [CrossRef] [PubMed]

52. Ma, Y.; Qiao, X.; Zeng, R.; Cheng, R.; Zhang, J.; Luo, Y.; Nie, Y.; Hu, Y.; Yang, Z.; Zhang, J.; et al. Irisin promotes proliferation but inhibits differentiation in osteoclast precursor cells. Faseb J. Off. Publ. Fed. Am. Soc. Exp. Biol. 2018. [CrossRef] [PubMed]

53. Morey-Holton, E.R.; Globus, R.K. Hindlimb unloading rodent model: technical aspects. J. Appl. Physiol. (1985) 2002, 92, 1367-1377. [CrossRef] [PubMed]

54. Bouxsein, M.L.; Boyd, S.K.; Christiansen, B.A.; Guldberg, R.E.; Jepsen, K.J.; Muller, R. Guidelines for Assessment of Bone Microstructure in Rodents Using Micro-Computed Tomography. J. Bone Miner. Res. 2010, 25, 1468-1486. [CrossRef]

(C) 2020 by the authors. Licensee MDPI, Basel, Switzerland. This article is an open access article distributed under the terms and conditions of the Creative Commons Attribution (CC BY) license (http://creativecommons.org/licenses/by/4.0/). 